\title{
CFD ANALYSIS OF DIFFUSER AUGMENTED WIND TURBINE USING DYNAMIC MESHING
}

\author{
Amit Kumar \\ Aeronautical \& Automobile Dept., \\ Manipal Institute of Technology, \\ Manipal, India
}

\author{
Guru Teja Chilukoti \\ Aeronautical \& Automobile Dept., \\ Manipal Institute of Technology, \\ Manipal, India
}

\begin{abstract}
Theoretically it is proved that the performance of bare wind turbine cannot exceed the Betz-Joukowsky limit but this limit can be exceeded if the turbine is placed inside the optimized diffuser. This research work presents the analysis of diffuser augmented wind turbine (DAWT) using dynamic meshing where the turbine was rotated with the effect of wind and the angular velocity of the wind turbine was calculated for different flow velocities and this result was compared with the results of bare wind turbine. The DAWT results show more than $700 \%$ increase in turbine angular velocity. CATIA V6 was used to design the wind turbine and ANSYS Fluent was used to carry out the simulation.
\end{abstract}

Keywords- Wind Turbine, DAWT, Diffuser, Angular Velocity.

\section{INTRODUCTION}

Wind has become one of the areas for developing viable energy as the cost of the non-renewable energy and the harm of their use has increase. Wind turbines are the traditional means of extracting the energy from wind. DAWT is a concept of augmenting the velocity of flow at rotor plane while extracting the power from wind at the same free stream velocity. When the conservation of mass principle is applied, the increase in the velocity of the flow at the rotor plane would mean that a larger cross-sectional area stream tube is captured unlike in a comparable conventional free stream wind turbine [1,2]. Since power output is a cubic function of velocity, an increase in velocity leads to a substantial increase in power output [3], shown below.

$$
P=\frac{1}{2} \rho_{\infty} A_{r e f} C_{P} U_{\infty}^{3}
$$

Where $\rho_{\infty}$ is the free stream density, $A_{\text {ref }}$ is the reference area, $c_{p}$ is the power factor, $U_{\infty}$ is the free stream velocity. The power augmentation factor is the ratio of power extracted with the diffuser to the power extracted by the same rotor without the diffuser. In preliminary feasibility studies, power augmentation factor by the diffusors are as high as seven has been predicted [4]. With the concept of DAWT being the new scope for augmentation much of the research was done at
University of Auckland in New Zealand and Grunmman Aerospace Corporation, whose focus was on the diffuser design and its integration with the wind turbine and not on the rotor optimization theory which was the prior interest for augmentation $[5,6]$.

Research done later than above mentioned are mainly on optimizing the diffuser for its efficiency and some on the turbine blade itself. So as to develop and find ways to optimize, work was done by Van Bussel and G.J.W whom developed a simple momentum theory for DAWT's with some straight assumptions like there is no viscous wake mixing process behind the diffuser but the negative back pressure effects were taken into account and concluded that if a substantial low "Back pressure level" can be achieved at the diffuser exit, significant increase in the turbine performance would be observed [7]. And the supporting research for the Van Bussel and G.J.W 's conclusion, work was done by Ken-ichi Abea from Kyushu University Japan, on DAWT's with a Flanged end, they concluded that the flange would create the necessary low back pressure levels and wake mixing that high augmentation factors were achieved $[8,9,10]$. And as far the blade optimization work is considered paper was published by Jerson R.P. Vaz, David H. Wood on "Aerodynamic optimization of the blades of diffuseraugmented wind turbines" they used simple blade element theory with additions being the diffuser efficiency and velocity ratio which help in determining the increase in wind speed at the roto plan due to diffuser [11]. Jerson R.P.Vaz was also in a research group prior to his work in [11] whom developed a 1D mathematical model in blade design using blade element momentum model with low computational cost [12].

In research done till now on DAWT's using Computational Fluid Dynamic (CFD) to simulate various models, different geometries of both diffuser and the blade of the turbine, the method followed in determining the increase in efficiency was setting the turbine within the augmentation diffuser at a fixed RPM and getting the flow speeds before and after the rotor plane, but this method doesn't truly capture true motion of the flow stream or the blade rotation, i.e. the blade propels the stream rather than the stream propelling the blade where the latter is the real case scenario, but if a method is to be used in which the flow propels the blade it would be much closer to that of a real scenario (excluding the Fluid Structure Interactions 


\section{International Journal of Engineering Applied Sciences and Technology, 2019 \\ Vol. 4, Issue 3, ISSN No. 2455-2143, Pages 81-84 \\ Published Online July 2019 in IJEAST (http://www.ijeast.com)}

such as bending and loading). Our aim is to produce results for DAWT's using this method on the Computational Fluid Dynamic Simulations. For this we used the ANSYS Fluent's Dynamic Meshing model.

\section{METHODOLOGY}

For the analysis, the 3D wind turbine was designed in Catia V6 using a S809 airfoil with a diameter of $1640 \mathrm{~mm}$, this blade isn't a hybrid blade and doesn't have any twist radially but is tapered, as shown in Fig 1. Ansys 18 was used for the fluid simulation, the geometry for the non-diffuser domain (Fig 2) and the diffuser domain (Fig 3) were designed within Ansys package (Design modeller), within the non-diffuser domain the turbine is placed at about $3000 \mathrm{~mm}$ from the inlet and $5000 \mathrm{~mm}$ from the outlet. The meshing for the non-diffuser domain and the diffuser domain were done in the built-in meshing tool of Ansys, a total of 2600000 elements and 2700000 elements were found in the non-diffuser domain and diffuser domain respectively, the cross-sectional view of the meshed domains can be seen in Fig 4 and Fig 5, as far the analysis Fluent was used within Ansys. The K-epsilon viscous model was selected for both the analysis since the flow velocity is high onside the diffuser, the Reynolds number is also high and this model gives more accurate results for high Reynolds number [13], i.e. near wall (turbine blade and diffuser) conditions are to be captured. The dynamic meshing and its properties were enabled to simulate a turbine that is being propelled by the incoming flow through the inlet.

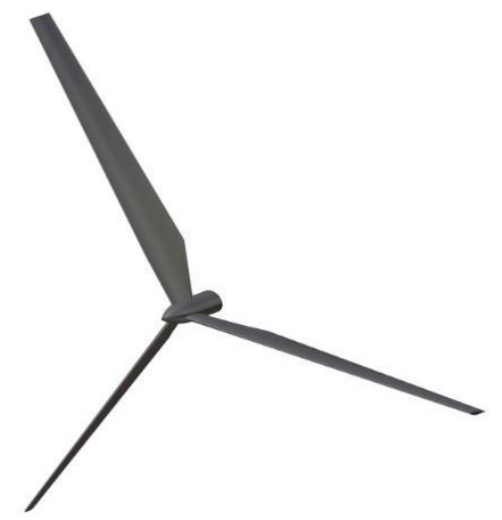

Fig 1: Iso view of the S809 turbine.

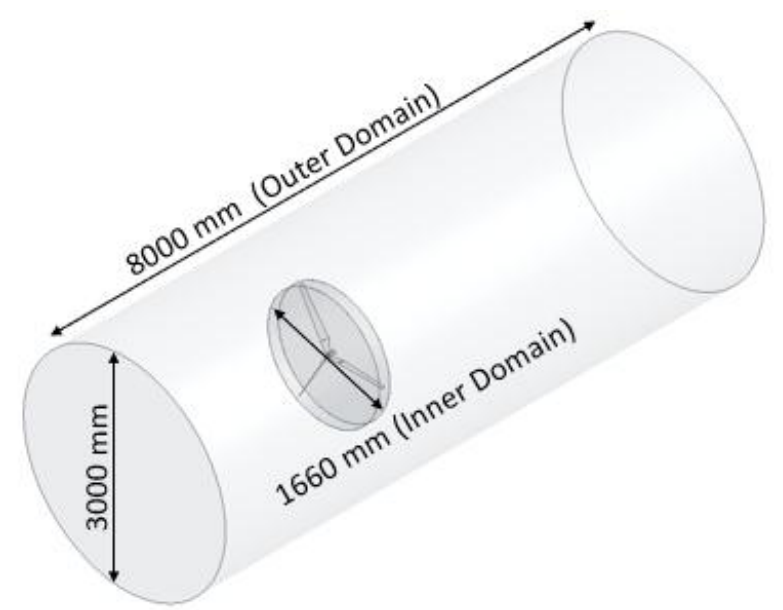

Fig 2: Geometry of the non-diffuser domain.

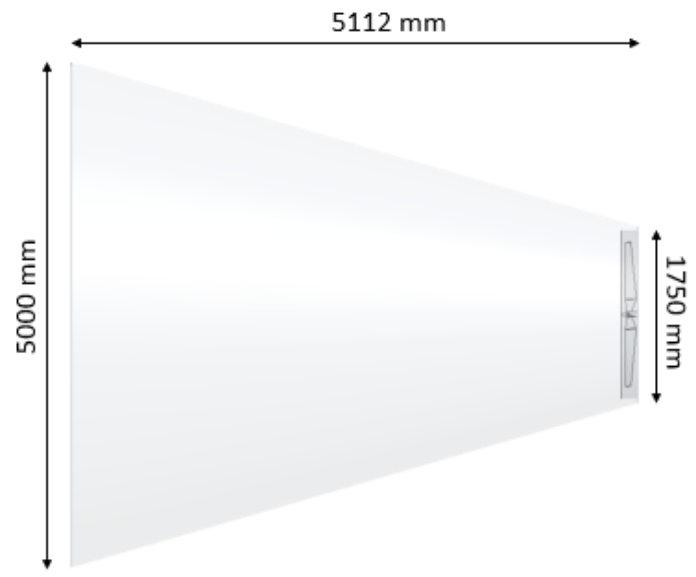

Fig 3: Geometry of the diffuser domain.

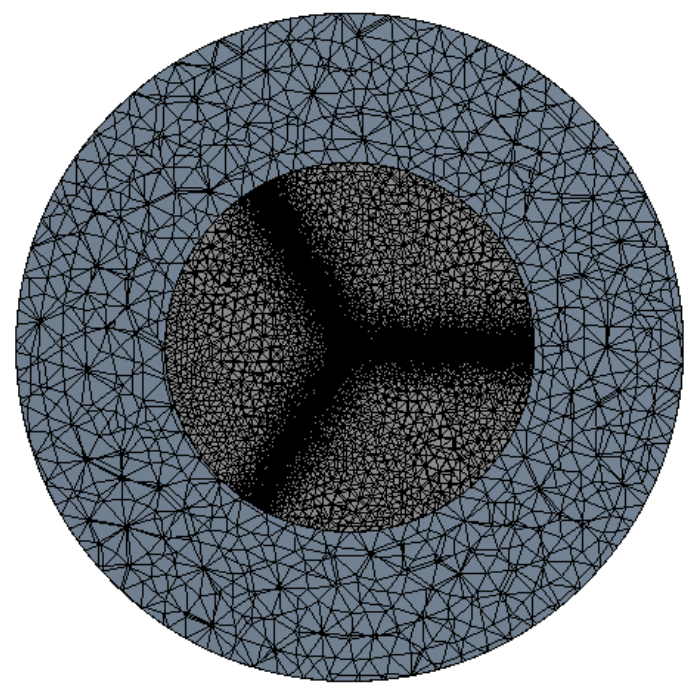

Fig 4: Cross-sectional mesh of the non-diffuser domain. 


\section{International Journal of Engineering Applied Sciences and Technology, 2019 \\ Vol. 4, Issue 3, ISSN No. 2455-2143, Pages 81-84 \\ Published Online July 2019 in IJEAST (http://www.ijeast.com)}

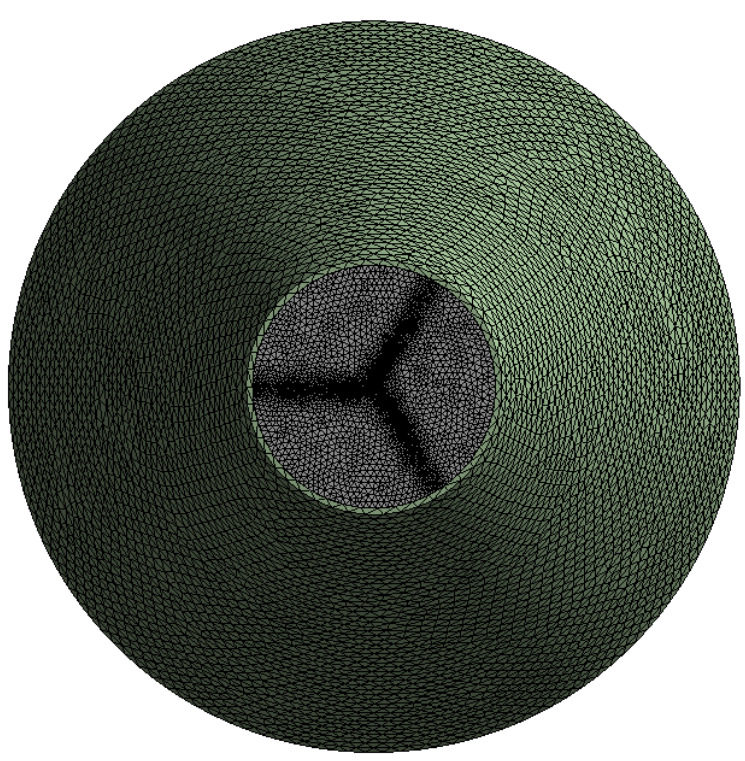

Fig 5: Cross-sectional mesh of the diffuser domain.

\section{RESULTS AND DISCUSSION}

The wind turbine was tested for different flow velocities ranges from $1 \mathrm{~m} / \mathrm{s}$ to $15 \mathrm{~m} / \mathrm{s}$. The change in velocity was observed more for higher velocities which varies as the square of the ratio of the radii of diffuser inlet to diffuser outlet. ANSYS Fluent calculate this result using the continuity equation [14] given below

$$
\frac{\partial}{\partial t} \oiiint_{\nu} \rho d v+\oiint_{S} \rho \boldsymbol{V} \cdot \boldsymbol{d} \boldsymbol{S}=0
$$

The above equation is an integral form of continuity equation where $\boldsymbol{V}$ is Fluid velocity, $\rho$ is fluid density, $\boldsymbol{d} \boldsymbol{S}$ is a vector elemental area, $d v$ is an elemental volume inside the control volume and $\mathrm{t}$ is the time.

The Fig 7 shows the contour of velocity variation inside the diffuser at inlet velocity of $5 \mathrm{~m} / \mathrm{s}$. The wind turbine angular velocity increase as the flow velocity increases as shown in Fig 8 , but the increase in angular velocity was observed more in case of DAWT because the flow velocity faced by turbine in case of DAWT is increased parabolically from its inlet velocity while the wind turbine without diffuser is facing only the given inlet velocity. Fig 9 presents the percentage increase in angular velocity of DAWT relative to wind turbine without diffuser. The percentage increase in RPM is increase as the flow velocity increases, it follows the parabolic curve similar to that of flow velocity inside the diffuser in Fig 6

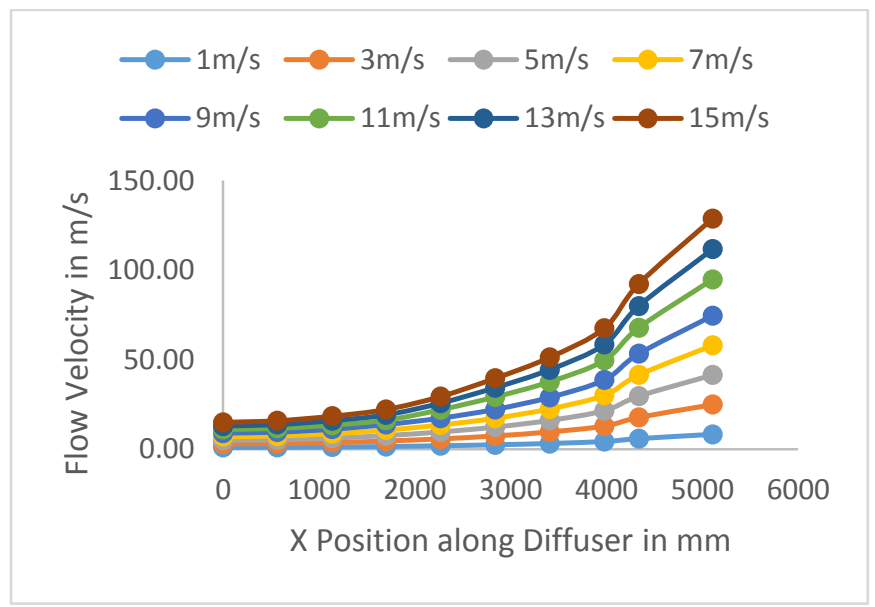

Fig 6: Flow velocity variation inside the diffuser.

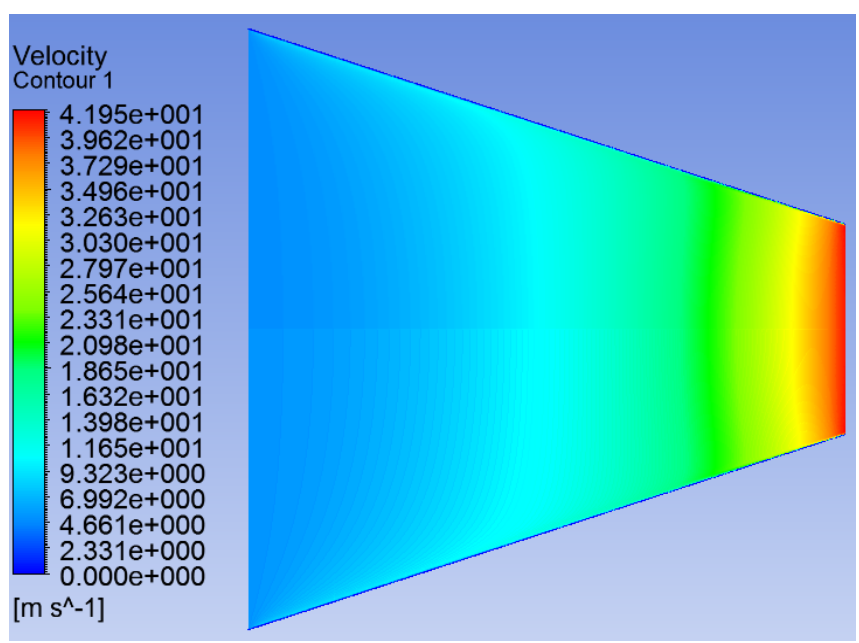

Fig 7: Flow velocity contour inside the diffuser.

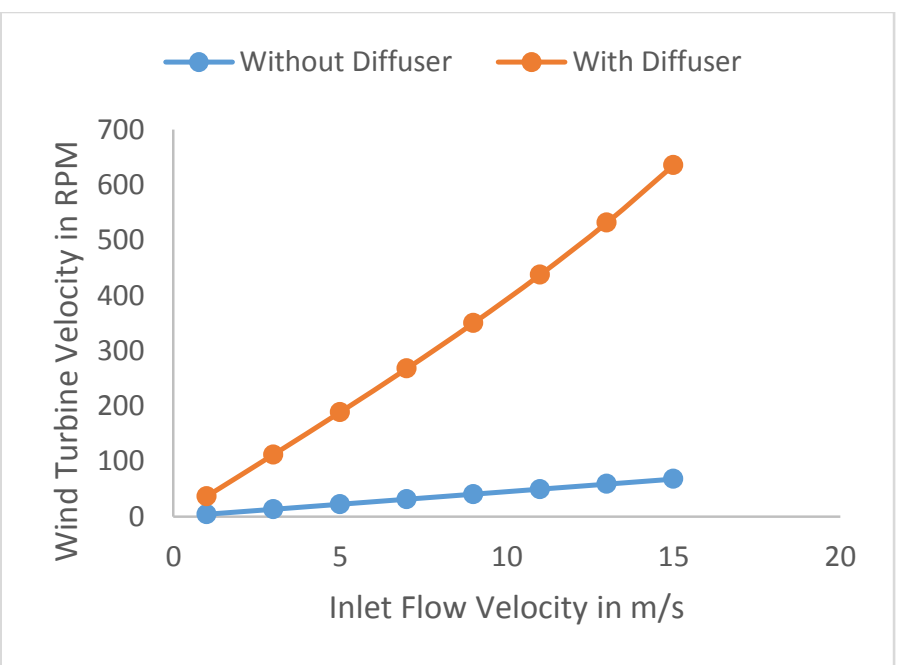

Fig 8: Wind turbine velocity variation with and without diffuser. 


\section{International Journal of Engineering Applied Sciences and Technology, 2019 \\ Vol. 4, Issue 3, ISSN No. 2455-2143, Pages 81-84 \\ Published Online July 2019 in IJEAST (http://www.ijeast.com)}

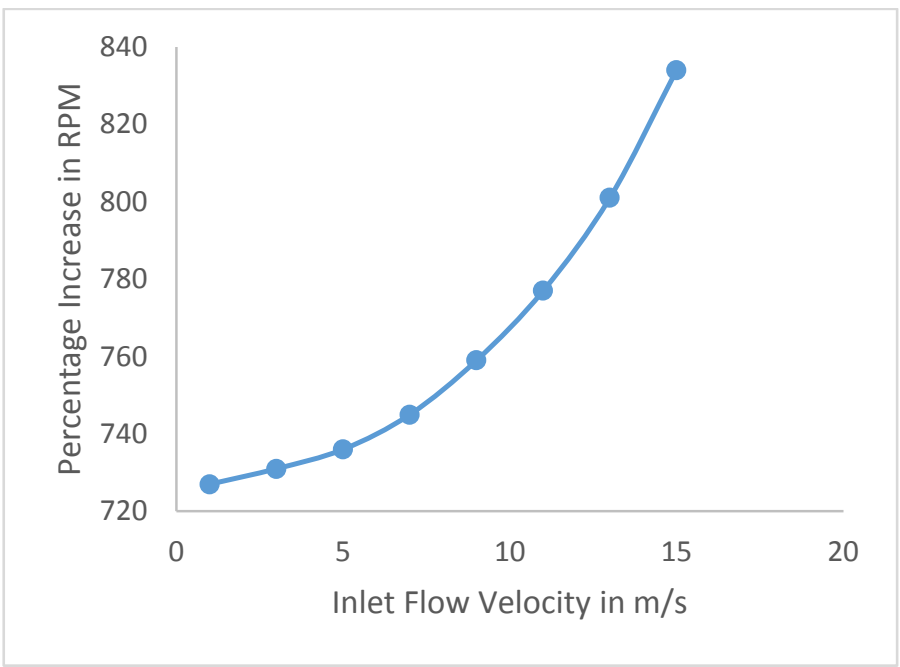

Fig 9: Percentage increase in RPM of DAWT relative to wind turbine without diffuser

\section{CONCLUSION}

This research work presents the CFD analysis of DAWT where the angular velocity was calculated for different flow velocities and compared with those of bare wind turbine. The analysis shows that the wind turbine performance can be significantly increased by placing it inside the optimized diffuser. Since the flow velocity variation inside the diffuser is similar to parabolic the percentage increase in RPM of DAWT also follows the similar trend. This increase in RPM of DAWT will also increase the power output significantly.

\section{REFERENCES}

[1] Phillips D. G. (2003). An Investigation on Diffuser Augmented Wind Turbine Design, Ph.D. thesis, University of Auckland.

[2] Manwell J. F., McGowan J. G. and Rogers A. L. (2010). Wind Energy Explained: Theory, Design and Application, Wiley,.

[3] Werle M. J. and Jr. W. M. P. (2008). Ducted Wind/Water Turbines and Propellers Revisited, Journal of Propulsion and Power, Vol. 24, No. 5, pp. 1146-1150.

[4] Badawy M. T. S. and Aly M. E. (2000). Gas dynamic analysis of the performance of diffuser augmented wind turbine, Sadhana, Vol. 25, No. 5, pp. 453-461.

[5] Phillips D. G., Flay R. G., and Nash T. A. (1999).Aerodynamic analysis and monitoring of the Vortex 7 diffuser- augmented wind turbine, IPENZ Transactions, Vol. 26, No. 1, pp. 13-19.

[6] Foreman K. M. (1981). Preliminary Design and Economic Investigations of Diffuser Augmented Wind Turbines (DAWT), Tech. rep., Grumman Aerospace Corporation.
[7] Van Bussel, G.J.W. (1999). An Assessment of the Performance of Diffuser Augmented Wind Turbines (DAWT's), 3rd ASME/JSME Fluid Engineering Conference FEDSM99-7830, San Francisco, USA.

[8] Ken-ichi Abea, Yuji Ohyab.(2004). An investigation of flow fields around flanged diffusers using CFD, Journal of Wind Engineering and Industrial Aerodynamics 92, 315-330

[9] Abe K., Nishida M., Sakurai M.A., Ohya Y., Kihara H., Wada E., Sato K. (2005). Experimental and numerical investigations of flow fields behind a small-type wind turbine with flanged diffuser. J. Wind Eng. Ind. Aerodynamics. 93, 951-970.

[10] Yuji Ohyaa, Takashi Karasudania, Akira Sakuraib, Kenichi Abeb, Masahiro Inouec. (2008) Development of a shrouded wind turbine with a flanged diffuser, Journal of Wind Engineering and Industrial Aerodynamics 96524 539.

[11] R.P. Jerson, Vaz, H. David, Wood. (2016). Aerodynamic optimization of the blades of diffuser-augmented wind turbines, Energy Conversion and Management 123, 35-45.

[12] Tavares Dias do Rio Vaz, Déborah Aline, Amarante Mesquita, André Luiz, Pinheiro Vaz, Jerson Rogério, Cavalcante Blanco, Claudio José, \& Pinho, João Tavares .(2014). An extension of the Blade Element Momentum method applied to Diffuser Augmented Wind Turbines, Energy Conversion and Management 87, 1116-1123.

[13] Z. Yang, T.H. Shih. (1993). New Time Scale Baed Kepsilon Model for Near-Wall Turbulence, AIAA Journal, Vol.31, No.7, 1191-1198.

[14] John D Anderson, Fundamentals of Aerodynamics. 